Article

\title{
Identifying the Determinants of Urbanization in Prefecture-Level Cities in China: A Quantitative Analysis Based on Spatial Production Theory
}

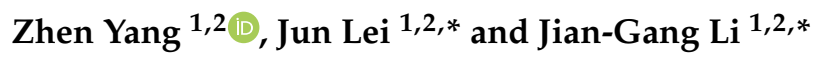 \\ 1 Xinjiang Institute of Ecology and Geography, Chinese Academy of Sciences, Urumqi 830011, China; \\ yangzhen16b@163.com \\ 2 College of Resources and Environment, University of Chinese Academy of Sciences, Beijing 100049, China \\ * Correspondence: leijun@ms.xjb.ac.cn (J.L.); lijiangang16@mails.ucas.ac.cn (J.-G.L.); \\ Tel.: +86-0991-7827321 (J.L.); +86-0991-7827368 (J.-G.L.)
}

Received: 3 January 2019; Accepted: 18 February 2019; Published: 25 February 2019

check for updates

\begin{abstract}
China's urbanization has attracted considerable academic attention. However, more work is required to understand and examine the driving mechanisms of urbanization, especially within the context of the transition from socialism. We used a regression model and a geographical detector technique to determine the direction and strength of factors influencing urbanization in prefecture-level cities in China. We found that China's urbanization development model has two characteristics: administrative hierarchy and spatial agglomeration. Based on our conceptual framework, we identified the positive effect exerted by the real estate investment and per capita fiscal expenditure on urbanization, as well as the negative impact exerted by the urban-rural income ratio. The results revealed that China's urbanization is a hybrid process: the forces from power and capital contribute to high levels of urbanization. When comparing the strength of the factors influencing urbanization between coastal and inland cities, we found that real estate investment and per capita fiscal expenditure in coastal cities have a greater impact on urbanization than in inland cities. In contrast, the impact of the urban-rural income ratio on urbanization is larger in inland cities than in coastal cities. A close examination on the factors influencing China's rapid urbanization is the key to further advancing our understanding of the dynamic mechanisms of China's urbanization. Our findings can help Chinese policy makers formulate more detailed urbanization strategies with consideration of regional characteristics.
\end{abstract}

Keywords: urbanization; influencing factors; production of space; prefecture-level cities; China

\section{Introduction}

Urbanization is one of the most remarkable changes in human history [1]. Many scholars from different fields have contributed to attempt to depict urbanization [2-10]. Since World War II, the trend in urbanization around the world has continued. The world's population is increasingly located in cities [5]. According to the latest projection and estimate of the world urbanization prospects issued by the Department of Economic and Social Affairs of the United Nations Secretariat, the world's urban population continues to grow at a higher rate than the world's total population. As of 2018, 4.2 billion people, about $55 \%$ of the total world population, had become urban residents. Compared with 1950 , this proportion has increased by $25 \%$. By $2050,68 \%$ of the world population is projected to live in urban areas [11]. Urbanization is progressing rapidly in underdeveloped areas, and the urban population of developing countries is anticipated to grow by an average $2.3 \%$ per year from 2000 to 2030. During this period, almost all of the world's population growth will be absorbed by cities in less 
developed regions [3]. With the continuous acceleration of economic globalization, global urbanization, and urban systems are undergoing an important transformation and reconstruction. The urbanization in developed countries has basically entered a mature stage, and the focus of urbanization has shifted to developing countries, especially China's unique urbanization path, which has received considerable attention [5,12].

As the most populous country, China has the largest urban population in the world [3]. For a long time, China's urbanization rate has been lower than the world average, but the rate has recently caught up with the world average. In 2008, humanity reached a new milestone, when the global urban population surpassed the rural population for the first time in history [5,13]. In 2011, China's urbanization successfully crossed the historical turning point of $50 \%$. China is urbanizing at an unprecedented scale and rate. This is perhaps the greatest human-resettlement experiment in history [7]. Throughout the history of urbanization from the founding of the People's Republic of China to the Reform and Opening-up, China's urbanization process has undergone many twists and turns. It is manifested in the 'spurious urbanization' and 'overurbanization' during the Great Leap Forward (1958-60) and the decline in urbanization during the Cultural Revolution (1966-76). In general, China's urbanization process can be divided into two stages: pre-reform and post-reform. In the pre-reform period (1949-1977), due to strict control of rural-to-urban migration, China's urbanization growth rate and level were both low [14]. In 1949, when the People's Republic of China was founded, the urbanization rate in China was $10.6 \%$. In 1979, China's urbanization rate was $19 \%$, and only increased by less than $9 \%$ in 30 years. Since the Reform and Opening-up (1978-current), affected by a series of internal and external factors, China's urbanization level has increased rapidly [15-20], especially in recent years, and the average annual growth rate of urbanization has exceeded $1 \%$. Note, Reform and Opening-up is a policy of internal reforms and opening up to the outside world initiated by China at the Third Plenary Session of the 11th Central Committee in December 1978. China's internal reforms began in the rural areas. In November 1978, Xiaogang Village, Fengyang County, and Anhui Province, implemented the household contract responsibility system of "dividing farmland into households and taking responsibility for its own profits and losses", which opened the curtain of China's internal reforms. In cities, the autonomy of state-owned enterprises has been significantly improved. Now, the country has steadily entered the rapid urbanization development stage, and is critically transforming from the rapid growth of urbanization rate to the improvement in urbanization quality [21]. In March 2014, the "National New Urbanization Plan (2014-2020)" was introduced, and the optimization and reconstruction of the urban population distribution pattern has become one of the key areas of national strategic decision-making. Studying the spatial differentiation patterns, influencing factors, and regional characteristics of urbanization can provide a scientific basis for people-oriented urbanization, and can provide useful references for local governments to promote urban development according to local conditions [21].

Due to the regional differences in geographical factors and the unbalanced development strategies implemented by the governments, the urbanization levels in China demonstrate evident spatial differentiation [22]. Taking 2010 as an example, the urbanization rate in Shenzhen City was 100\%, whereas that of Zhaotong City was only $18.7 \%$. The huge gap between the eastern coastal cities with high urbanization levels and the inland cities with low urbanization levels is unfavorable for the development of urbanization in China. This polarized urbanization model has exceeded the development potential of China's urbanization, thereby negatively impacting on the quality of urbanization.

The factors influencing urbanization are important and closely related to the level of urbanization. Urbanization is a complex dynamic process, which is influenced by government policies, market, economic agglomeration, and foreign investment [23]. Urbanization in the pre-reform period (1949-1977) is different from the post-reform period (1978-current) [23,24]. Before Reform and Opening-up, China's urbanization was characterized by state-sponsored single-track urbanization, and the market played a very weak role. The development of urbanization was completely 
subjected to the national industrialization strategy, and urbanization participants lacked the rights to choose independently under the urban-rural dual structure system. Since the early 1980s, the influencing factors have changed significantly, manifested as the co-existence of dual-track urbanization: spontaneous urbanization (bottom-up urbanization) and state-sponsored urbanization (top-down urbanization) [23]. The concept of dual-track urbanization has been successfully applied to the study of urbanization process in China, the Pearl River Delta, and Fujian Province [23-26]. Since the mid to late 1980s, foreign capital has become a new driving force of urbanization in China [24,27], and the driving forces of China's urbanization have gradually turned into a multi-driving one [28-31]. Zhang [32], for instance, found that market force and administration force are two important driving forces since 1978. Heikkila [33] argued that political devolution, demographic changes, globalization, and technological change are the major influencing factors for China's rapid urbanization. Using a disequilibrium supply and demand model, Young and Deng [34] explored the trends in China's urbanization process and found that China's sustained economic growth and profound institutional changes have been the most critical forces in rapid urbanization since 1978. Zhang [30] concluded that the main driving forces of China's urbanization are urban policy changes, economic growth, and structural changes. Population mobility has had an increasingly significant impact on urbanization in China [15,35]. In summary, the aforementioned studies expanded the multi-dimensional perspectives and approaches of urbanization dynamic mechanisms, which are important to optimize urban-rural population distribution. However, the previous studies mainly focused on the impacts of market force, intrinsic force, and exterior force on urbanization, while ignoring the needs of vulnerable groups, which is inconsistent with the people-oriented urbanization advocated by the new-type urbanization; and is also not conducive to achieving the goals of three "100 million people" [10,23]. The goal of this policy is to promote about 100 million agricultural-based people to settle in cities and towns, transforming city villages and shantytowns, where about 100 million people currently live, and guiding about 100 million people to settle in nearby towns and cities in Central and Western China.

The above studies on the factors influencing urbanization in China were completed from different theoretical perspectives, including the theory of economic development and the theory of urban-rural differences. Agglomeration economy and developmental economics theories can also provide useful theoretical perspectives for the study of the influencing factors of urbanization in China. Notably, these theories were primarily developed from the study of urbanization in Western developed countries. However, the study of China's urbanization experience shows these theories while providing useful insights into the factors affecting urbanization, they are not sufficient, not only because they reflect the unique Western perspective, but also because China's historical, political, and economic environment are quite different from that of the West. Our argument is based on the fact that China, as a socialist country, does not fully reflected the characteristics of a developed market economy in the process of opening up its economy to market conditions [36]. As a socialist country in transition, China's market-oriented reform adopts a gradual development process. Therefore, we have reason to think that within a broader framework of political economy theory, the theoretical approaches emphasizing the role of institutions in economic, social, and political change can provide the most valuable theoretical insights into the factors influencing urbanization in China.

We find that Lefebvre's theory of space of production [37], which emphasizes the importance of economic and political processes in spatial production, is most helpful in delineating the determinants of urbanization in China. Although the theory of spatial production not only focuses on urban issues, urbanization is at its core. Therefore, using the theory of spatial production to explore and analyze urbanization has become the focus of space production. This theory not only integrates the traditional factors influencing urbanization, but also considers the needs of vulnerable groups in the context of capital alienation society (space). With the acceleration of urbanization, China's urban spatial form and structure have undergone dramatic transformations [38], and new theoretical explanations and responses are urgently needed, providing the opportunity for the application of this theory in China. 
As a critical social or urban theory, the production of urban space refers to the process through which economic (capital), political (power), social (class), and other political and economic factors reshape urbanization, so that the urban space becomes their process and production [39,40]. In short, the urbanization process is actually a spatial production process, and there is a dialectical relationship between urbanization and space production. Rapid urbanization not only changes the physical space — such as landscapes, land use, the urban built environment, etc.-but also reshapes mental and imaginative space. Space itself is an important producer and driving force of urbanization [40]. Urbanization is a process through which capital, power, and class interact with urban space. There are many kinds of scales between production of space and urbanization [41], and there are both connections and differences between these scales [40]. Although a plethora of empirical studies have been carried out, from macro and micro levels using spatial production theory [39,42-47], few empirical studies have investigated the factors affecting urbanization based on this theory. The reason for this is that assessing the extent of space production is difficult when applying this theory. We attempted to fill the gap by empirically investigating the determinants of urbanization at prefecture-level in China with cross-sectional data based on spatial production theory.

The next question is: how do we relate this theory to the factors influencing urbanization? If we understand the production of urban space from the above three main factors (capital, power, and class), it will not be difficult, because, from a statistical point of view, there are some indicators corresponding these three factors. Building up on previous studies [40], we designed a simple index system to associate space production with the factors influencing urbanization. The rest of this article is organized as follows. The next section illustrates the data and methodologies used in this study, including the construction of conceptual framework, the initial selection of influencing factors, study area and data issues, and the research methods used. This is followed by a section outlining the research results. The next section provides a discussion of the findings. Conclusions are given in the last section.

\section{Data and Methodology}

\subsection{Study Area and Data Issues}

In 2010, China was composed of 337 prefecture-level units, including 287 prefecture-level cities, 50 regions, autonomous prefectures, and alliances. At present, the establishment criteria of prefecture-level cities include: (1) the population engaged in non-agricultural industries in urban districts is more than 250,000, of which more than 200,000 people are engaged in non-agricultural industries with non-agricultural household registration; (2) the total output value of industry and agriculture is more than 3 billion yuan, of which industrial output value accounts for more than $80 \%$; (3) GDP is more than 2.5 billion yuan; (4) tertiary industry is developed and its output value exceeds that of the primary industry, accounting for more than $35 \%$ of the GDP; and (5) local budgetary revenue is over 200 million yuan. With $48.57 \%$ of the land area, $93.90 \%$ of the total population, and $96.19 \%$ of the urban population in China, the prefecture-level cities account for $97.21 \%$ of the gross domestic product (GDP) [48,49]. As important carriers of regional strategy and policy, prefecture-level cities have played an increasingly significant role in the development of China's economy. According to different economic management systems, China can be divided into four economic zones: East, Central, West, and Northeast, which include 87,81, 85, and 34 prefecture-level cities, respectively. Figure 1 shows the location of the prefecture-level cities in China. There are obvious regional economic differences among the four economic zones. In 2010, the per capita GDP of the four economic zones in the eastern, central, western, and northeastern regions was 46,$621 ; 24,503 ; 25,511$; and 38,293 yuan, respectively. The per capita GDP of the eastern region was almost twice that of the central region.

The population data used in this study was collected from Sixth National Census conducted in 2010. The three socio-economic indicators used in this article were: real estate investment (REI) and urban-rural income ratio (URIR) from China Statistical Yearbook for Regional Economy 2011 and per 
capita fiscal expenditure (PCFE) derived from China City Statistical Yearbook 2011. We only selected 2010 as the research year, and did not carry out cross-sectional data comparison for different years or panel data analysis. The reasons for this are: first, China's census is conducted every 10 years, and the latest national census was completed in 2010. We used census data instead of annual statistical reports, for the completeness and accuracy of the data, and to better represent the true number of residents in each prefecture-level city. Annual statistical reports compute the population based on their household registration status, and census data calculate the urban population and total population according to their residence [50,51]. For the cities with net population inflow, the number of permanent residents is much larger than their registered residents, such as large cities in the eastern coastal areas, while for the cities with net population outflow, their registered residents are much larger than their permanent residents, such as many cities in Henan Province. Second, since 2000, the administrative scope of prefecture-level administrative units in China has changed dramatically. Mainly reflected in the establishment of prefecture-level cities in the revocation areas and the newly established prefecture-level cities, this change in scope has created challenges for data comparison before and after the changes, and more importantly, results in missing research data.

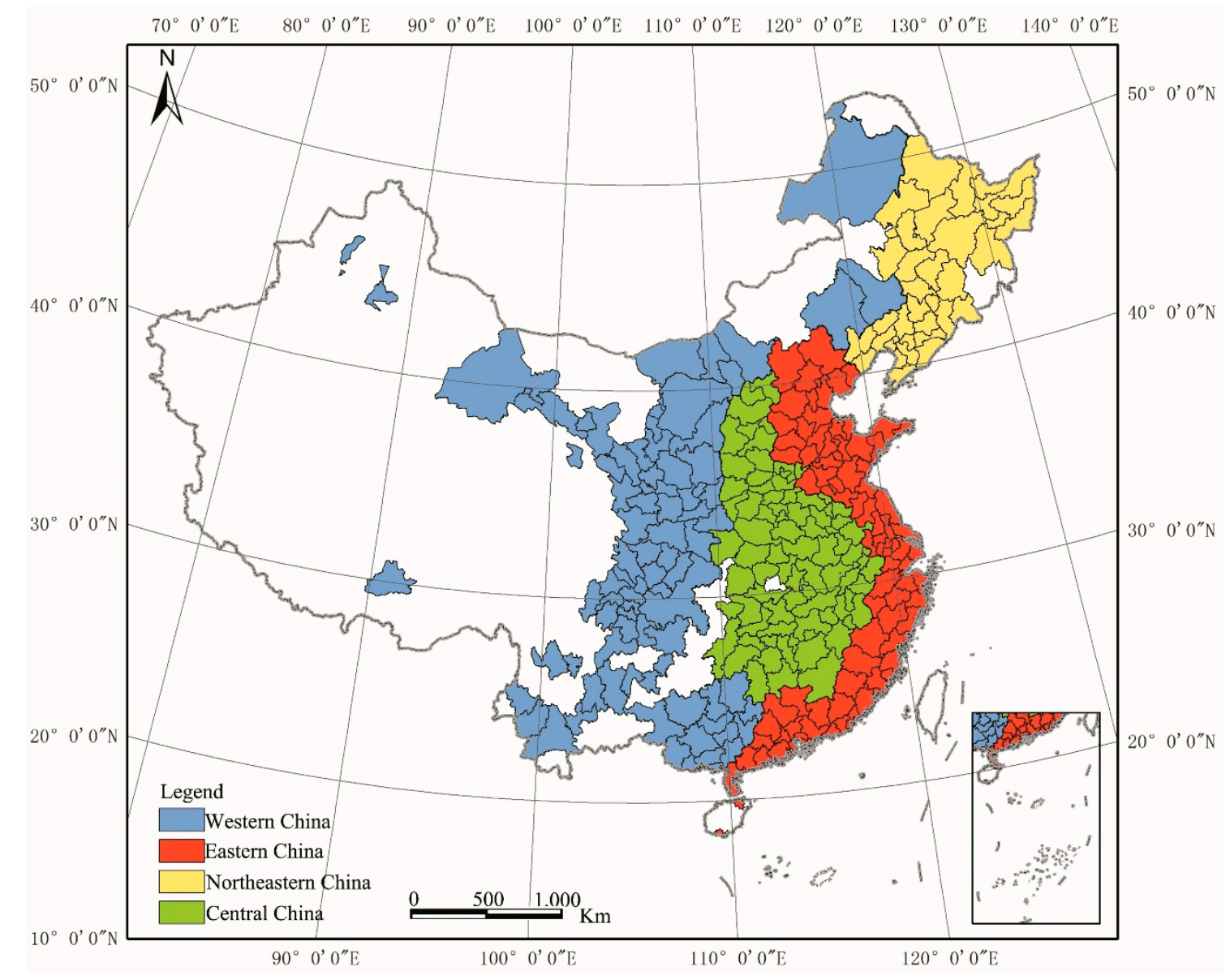

Figure 1. Location of prefecture-level cities in China.

\subsection{Conceptual Framework and Preliminary Selection of Influencing Factors}

Although different studies have identified the impacts of internal and external forces on China's urbanization, we developed a comprehensive conceptual framework in this study based on Lefebvre's theory of spatial production; because it provides a comprehensive model with different driving forces from a political economy perspective. Figure 2 shows the conceptual framework used in this paper. The analysis process was as follows: we used 287 prefecture-level cities as research units. Then, we began by selecting a set of influencing factors from three aspects: capital, power, and class. Multiple 
linear regression was used to determine the significance and direction of the determinants. Finally, the significant factors were examined in more detail using a geographical detector technique.

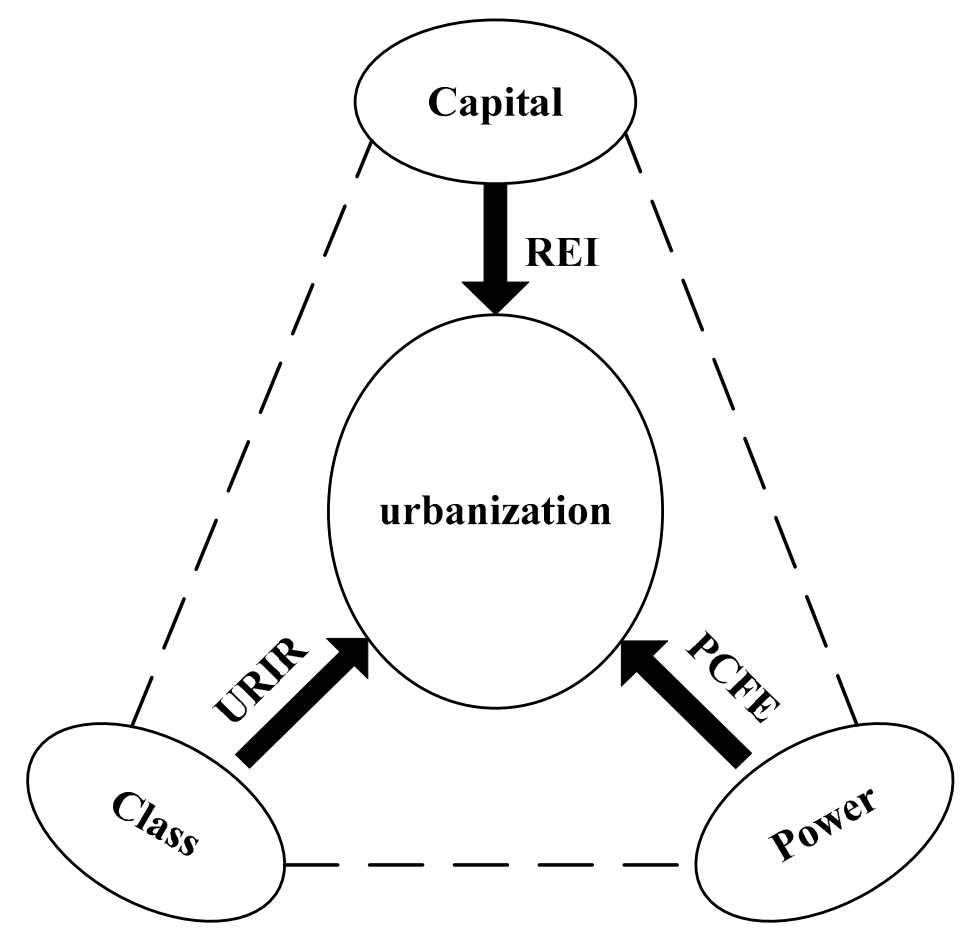

Figure 2. Conceptual framework of urbanization in transitional China.

We selected a set of simple but important exploratory variables in relation to urbanization level. In this indicator system, capital is represented by one indicator: real estate investment, power is represented by the per capita financial expenditure, and the indicator that characterizes class is urban-rural income ratio. Urbanization rate refers to the ratio of urban population to total population. With the expansion and deepening of Reform and Opening-up, the force from 'outside' is gradually increasing [27]. Since 1978, the foreign capital inflows have changed the traditional process whereby the government is the major driver in the process of urbanization, especially in the Pearl River Delta region. Zhang [30] also found that foreign direct investment (FDI) inflows contribute significantly to the differences in coastal-inland urbanization. Although globalization has gradually increased its impact on the urbanization process in China, China has a vast territory, and FDI is seriously unevenly distributed in the eastern, central, and western regions. FDI is largely concentrated in the eastern coastal areas, which is an important driving force for its urbanization process. The vast central and the western regions have attracted less FDI, which has had little effect on their urbanization. Therefore, China's urbanization process is still mainly an endogenous process [52], largely relying on endogenous production input, the domestic consumer market, and its own social development [53]. REI and FDI have a strong collinearity, which is also an important reason why we did not choose FDI as the explanatory variable. Variable meanings and basic statistics are listed in Table 1. The reasons for selecting variables are provided in the following sections.

\subsubsection{Real Estate Investment (Capital) and Urbanization}

As a material carrier of urban development and an important source of funds for urban construction, the real estate industry plays a pivotal role in increasing employment and stimulating domestic demand. A healthy real estate industry can further enhance the functions of the city and promote the rapid development of urbanization [54]. O'Sullivan [55] studied the relationship between the real estate industry and urbanization from the perspective of urban location; and drew the 
conclusion that real estate industry development and urbanization process are mutually influenced. Lampard [56] analyzed the impact of the real estate industry on urbanization, reporting that changes in housing prices led to corresponding changes in labor costs, which in turn affected the urban population and urbanization process. Sun [54] argued that real estate development is Granger causality to urbanization. Liu et al. [57] found that real estate investment provides more opportunities for urbanization by providing more housing for citizens.

Table 1. Statistics of variables.

\begin{tabular}{ccccccc}
\hline Factors & Main Variables & Symbol & Mean & Std.Dev & Min & Max \\
\hline Capital & Real estate investment (10 ${ }^{8}$ Yuan) & REI & 165.08 & 300.77 & 3.14 & 2901.07 \\
Power & Per capita fiscal expenditure (Yuan) & PCFE & 4611 & 2157 & 1609 & 16427 \\
Class & Urban-rural income ratio & URIR & 2.55 & 0.62 & 1.37 & 4.62 \\
Urbanization & Urbanization ratio (\%) & UR & 51.56 & 16.17 & 18.71 & 100.00 \\
\hline
\end{tabular}

\subsubsection{Per Capita Fiscal Expenditure (Power) and Urbanization}

As an important source of funds to promote urbanization, fiscal expenditure is an important way to guarantee the construction of urban infrastructure and realize the equalization of basic public services. Liu et al. [35] argued that fiscal expenditure is an effective variable reflecting the role of various levels of governments in economic development. Linn [58] found that the rapid urbanization process in developing countries requires a large amount of financial support. The empirical research by Davis and Henderson [59] showed that urbanization and economic development are the basis for a country to move from an agricultural country to an industrial country. Government policies, such as fiscal policy, will directly affect the process of urbanization. Yu [60] used data from different years to quantify the support of fiscal policies for urbanization, and concluded that there is a co-integration relationship between fiscal revenue, expenditure, and urbanization. Similar study results are obtained by Liu [61]. For the urbanization construction with Chinese characteristics, the government's macro-control plays an important role, and public fiscal expenditure, as one of the most important means of governmental macroeconomic regulation and control, promotes urbanization construction in China.

\subsubsection{Urban-Rural Income Ratio (Class) and Urbanization}

From the perspective of rural surplus labor transfers, Todaro [62] claimed that the key to determine the continuous transfer of rural surplus labor to cities lies in the gap between urban and rural incomes expected by farmers. The higher the expectation, the more farmers are willing to go to cities, which is conducive to the increase in urbanization. Lewis [63] observed that the traditional, backward agricultural economy and modern, advanced industrial economy coexist in the dual economic structure is a common form of economic development in developing countries, resulting in a certain income gap between farmers and urban residents. The surplus rural labor flows to the city, which directly promotes urbanization. The empirical analysis by Cai and Yao [64] showed that the urban-rural income gap has a negative impact on China's urbanization level. Li [65] found that the urban-rural income gap and urbanization level are in a state of dynamic balance with each other. The deepening of income imbalance is the reason for the increase in urbanization, but it is not the main reason; simultaneously, the income gap will also promote urbanization process. As argued by Ye et al. [40], urban and rural are not only two types of space, but also two major social classes in China. The urban-rural income ratio is an important index for measuring the urban-rural income gap, which can promote or block the urbanization process. Promotion is largely reflected in the ability to trigger the rural residents' yearning for urban life and enhance their motivation to move to cities, and blocking is reflected by the high housing prices in cities being accompanied by high incomes, which places excessive living pressure on the poor and is not conducive to long-term settlement in cities. 


\subsection{Methodology}

\subsubsection{Multiple Linear Regression Model}

Multivariate linear regression model is widely applied to analyze the factors influencing urbanization [21]. The significance level of each factor in the model can be used as a criterion for identifying the main influencing factors. The equation for this model can be expressed as

$$
P=a_{0}+a_{1} F_{1}+a_{2} F_{2}+\cdots+a_{n} F_{n}
$$

where $F_{1}, F_{2}, \ldots, F_{n}$ are the various factors that affect urbanization; $a_{1}, a_{2}, \ldots, a_{n}$ denote the regression coefficients for each factor; $P$ refers to urbanization, and $a_{0}$ is the intercept for all factors.

\subsubsection{Geographical Detector Technique}

The geographical detector technique was used to quantify the driving mechanisms of urbanization. It is a creative combination of various dominant factors with existing statistical techniques and logical reasoning. Different from using a regression model to determine the direction of influencing factors, the geographical detector technique can detect the strength of influencing factors.

We used the geographical detector technique to assist in determining the strength of the influencing factors for the following purposes. First, the calculation results of the geographical detector technique include specific detection force values, which is better for interpreting the intensity of the factors affecting urbanization. Second, if the significance $t$-values of several factors in the regression model pass the hypothesis test, these factors are all significant. It is difficult to further distinguish which has a stronger influence, and using their regression coefficients to compare strengths of influencing factors is problematic. Because the magnitude of the regression coefficients depends on the selected factors themselves, the main manifestations are that the nature and units of the selected factors are different.

Therefore, determining the factor that has a stronger influence cannot be compared through regression coefficients. The geographical detector technique main advantage lies in fewer assumptions or restrictions $[66,67]$. In this paper, we assumed that if the urbanization level is affected by some factors, then the distribution of such factors may be consistent with the distribution of urbanization in space. The power of determinant $D=\{D i\}$ to the urbanization level effect $U$ can be expressed as

$$
P_{D U}=1-\frac{1}{n \sigma^{2} u} \sum_{i=1}^{m} n_{D, i} \sigma^{2} U_{D, i}
$$

where $P_{D U}$ is the decisive power of influencing factor $D ; n_{D, i}$ represents the number of prefecture-level cities in subareas, $n(n=287)$ denotes the number of prefecture-level cities in study area, $m(m=5)$ denotes the number of the sub-areas, $\sigma^{2} u$ is the global variance of the urbanization level in the study area, $\sigma^{2} U_{D, i}$ is the variance of the urbanization level in the sub-areas, and the interval of $P_{D U}$ is $[0,1]$. $P_{D U}$ indicates that the distribution of urbanization is random; the larger the value of $P_{D U}$, the greater the impact of $D$ on urbanization level.

\section{Results}

\subsection{Urbanization in Prefecture-Level Cities}

Figure 3 shows that the spatial differentiation pattern of China's urbanization demonstrates dual characteristics: spatial agglomeration and administrative hierarchy. The higher the administrative hierarchy, the higher the level of urbanization. The spatial differentiation of urbanization largely occurs between coastal urban agglomeration and inland urban agglomeration. Specifically, the urbanization level of coastal prefecture-level cities is higher than that of inland prefecture-level cities. 


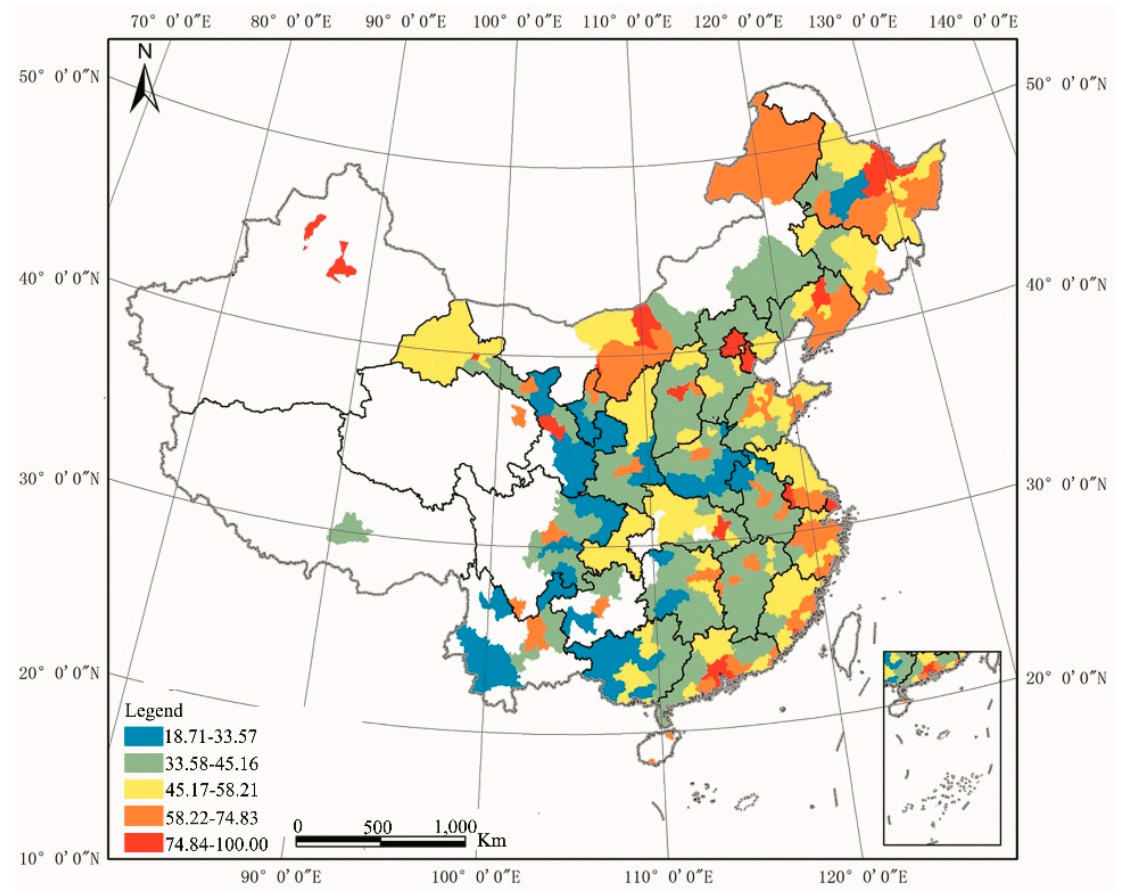

Figure 3. Spatial differentiation pattern of urbanization level in prefecture-level cities in China.

\subsection{Factors Influencing the Urbanization Level of China's Prefecture-Level Cities}

The REI indicates the impact of domestic capital on urbanization. Given the strong correlation between urbanization and domestic capital [40], we conducted a correlation analysis between the two. The result shows that the correlation coefficient, 0.464 , between urbanization and domestic capital is significant at the 0.01 level, revealing that REI considerably contributes to urbanization. In addition, we also completed a correlation analysis between urbanization and PCFE. At the significance level of 0.01 , the correlation coefficient was as high as 0.600 , which demonstrates that there is a close positive correlation between them. Public financial expenditure is the Granger cause of urbanization. The scale of public financial expenditure has a significant effect on urbanization and shows a stable positive effect.

Due to the unbalanced welfare systems, geographical development and resources are unevenly distributed between rural and urban areas, resulting in a huge income gap between urban and rural residents in China. Biased urban policies are the main reason for this gap [40]. The main tool was the household registration system (hukou system) introduced in 1958 [24,25,68]. The household registration system of the People's Republic of China is a household-based population management policy implemented by the People's Republic of China for its citizens. The household registration supports the legitimacy of a natural persons living in the local area. For a long time, the formulation and implementation of the population management policy of the People's Republic of China were based on this system. As an invisible barrier, the household registration system divides the two legal statuses of residents into non-agricultural population and agricultural population. Most of the agricultural population was found in rural areas, whereas the non-agricultural population was mainly confined within urban areas. The non-agricultural population enjoys many privileges such as education, housing, and employment provided by the state, whereas peasants were mainly responsible for their own survival and produce food for urban residents. Ultimately, the household registration system became an important institution in Chinese society, resulting in a huge income gap between people with two different identities.

Then, we conducted a correlation analysis between URIR and urbanization. The correlation coefficient is significant at the 0.01 level at -0.532 , which indicates that there is a significant spatial dislocation between urbanization and URIR. 
A regression model was constructed using the three factors mentioned above as independent variables. To avoid multicollinearity, tolerance, and variance inflation factor (VIF) tests were carried out. We found that the VIFs for the three explanatory variables were all less than 5, and their tolerances were close to 1 , indicating that there is no obvious multicollinearity among the explanatory variables.

The results of the model are reported in Table 2, from which the following points can be drawn.

Table 2. Determinants of urbanization level in all prefecture-level cities of China, 2010.

\begin{tabular}{|c|c|c|c|c|c|c|c|}
\hline Variables & $\begin{array}{c}\text { Non-Standardized } \\
\text { Coefficient }\end{array}$ & $\begin{array}{l}\text { Standard } \\
\text { Error }\end{array}$ & $\begin{array}{c}\text { Standardized } \\
\text { Coefficient }\end{array}$ & $t$-Value & Sig. & Tolerance & VIF \\
\hline Constant & 62.571 & 3.390 & & 18.459 & 0.000 & & \\
\hline REI & 0.010 & 0.002 & 0.190 & 4.353 & 0.005 & 0.793 & 1.260 \\
\hline PCFE & 0.003 & 0.000 & 0.441 & 10.135 & 0.000 & 0.797 & 1.255 \\
\hline URIR & -10.887 & 1.046 & -0.414 & -10.405 & 0.000 & 0.950 & 1.053 \\
\hline \multicolumn{8}{|l|}{ Statistical Test } \\
\hline $\mathrm{R}^{2}$ & 0.573 & & & & & & \\
\hline Adjusted $\mathrm{R}^{2}$ & 0.569 & & & & & & \\
\hline $\mathrm{F}$ & 126.804 & & & & & & \\
\hline
\end{tabular}

First, the estimated results of the regression model are satisfactory. The $\mathrm{R}^{2}$ is about $57 \%$, which indicates that the model has a reasonable explanatory power. Compared with the previous studies, 14 variables explained less than $75 \%$ of the factors influencing county urbanization in China [21], highlighting the rationality of selecting explanatory variables in this paper. The significance of REI conforms to our objective understanding and theoretical premises mentioned above. Real estate is the factor affecting urbanization. The development of the real estate industry provides the necessary space for production, living, housing, and commerce for the urbanization process and lays an important material foundation for the development of urbanization.

Second, PCFE is significantly positively correlated with urbanization level, which is in alignment with the expected direction. The impact of public financial expenditure on urbanization is largely manifested in the direct and indirect effects. Public financial expenditure, as an important source of funds to promote urbanization, is an important method of guaranteeing the construction of urban infrastructure and realizing the equalization of basic public services. However, the tax-sharing reform implemented in 1994 led to the unreasonable division of financial affairs between the central and local governments. The local government's fiscal revenue was insufficient, and local urbanization construction needed a large amount of financial support. Given this circumstance, local governments often adopted land financial means to increase fiscal revenue to promote local infrastructure construction, which indirectly promoted the increase in urbanization level.

Third, the coefficient of URIR is statistically significant and negative in Table 2. This means that the income gap between urban and rural residents is closely related to the level of urbanization; the smaller the income gap between urban and rural residents, the higher the level of urbanization; the greater the income gap between urban and rural residents, the lower the level of urbanization. We can obtain better understanding from a set of data. In 2010, the urbanization rates of the eastern, central, western, and northeastern regions were 59.94, 43.72, 44.31, and 57.26\%, respectively, and their corresponding urban-rural income ratios were 2.36, 2.67, 3.33, and 2.10. At present, the urbanization in the eastern coastal areas of China has reached a fairly high level, with a relatively high urban-rural integration level and a relatively small urban-rural income gap, whereas urbanization rates and urban-rural integration levels in the central and the western regions are both low, and the increase in urbanization occurs at the expense of agriculture and farmers' interests.

Overall, the estimated results of the model indicate that market and government forces are two important factors influencing China's urbanization process. The dynamic mechanisms of China's 
urbanization have been changing with the development of productivity. Before the introduction of the Reform and Opening-up, the government-led urbanization model played a decisive role. Since 1978, the government and market-led urbanization models have coexisted [24]. Conversely, URIR is identified as having an inhibitory effect on urbanization level. So, capital and power jointly manipulate the process of the spatial production of urbanization, which leads us to rethink a prominent problem in the process capital accumulation of China's urbanization, or rather, the squeezing and even deprivation of rural space and farmers' rights. In order to rapidly improve the urbanization level, the urban-rural dual structure and the imbalances in social and economic development are artificially manufactured, especially in the central and the western regions.

After identifying the significance and direction of the underlying factors affecting urbanization, we further estimated the strength of these factors. The above research units for the regression model, including all explanatory variables in the analysis, are all prefecture-level cities. However, changes in these explanatory variables may, to some extent, mask the regional variations in the urbanization level and their related determinants. According to the social and economic development conditions, China can usually be divided into developed eastern coastal areas and underdeveloped inland areas [69]. The numbers of prefecture-level cities in eastern coastal and inland areas are 115 and 172, respectively.

According to their original values, each factor can be divided into five categories in geographical space from low to high: low (10\%), low-middle (20\%), middle $(40 \%)$, high-middle $(20 \%)$, and high $(10 \%)$. There is no uniform standard for the classification of influencing factors. The values of the influencing factors in this paper are as follows: from low to high, the prefecture-level cities that account for 10, 20, 40,20, and 10\% of the total number of research units are assigned 1, 2, 3, 4, and 5, respectively. We could also assign values of $5,4,3,2$, and 1 , respectively, which would not affect the detection results. Based on such a classification principle, we delineated thresholds for each factor, and their spatial distribution patterns are displayed in Figure 4. Table 3 shows the strength of the potential influencing factors for all prefecture-level cities, coastal cities, and inland cities based on the geographical detector technique. The results reveal that there is a significant difference in the strength of each influencing factor. Specifically, the P value of the PCFE is the highest (0.3305), demonstrating that PCFE (power) is the core driving force of the uneven urbanization level at the prefecture-level in China. The P value for the REI (0.3199) is also relatively high, whereas the P value for the URIR is the lowest (0.2678). This implies that the rapid development of urbanization in China is the result of the interaction between government (administration force) and market (market force), which is consistent with the regression analysis conducted above.

We also observed differences in the strength of the influencing factors between coastal and inland cities. The impacts of REI and PCFE on urbanization in coastal cities are significantly greater than in inland cities. This shows that capital and power have a greater impact on the urbanization in coastal cities, reflecting the boosting role of strong real estate investment capacity in the developed coastal areas to the level of urbanization. To promote people-oriented urbanization, industrial support is an important foundation, and real estate is an important aspect for the realization of new-type urbanization. The development of the real estate industry provides a habitat for a large number of floating populations in coastal developed areas, which directly stimulates the increase in the urbanization level. The intensity of government fiscal expenditure reflects the level of urban public services. For migrants, going to work and enjoying urban life are their two main reasons for moving to an urban area. To a large extent, this explains the reasons for the higher urbanization level in coastal urban agglomerations such as the Yangtze River Delta, the Pearl River Delta, and Beijing-Tianjin-Hebei.

Compared with coastal cities, the impacts of REI and PCFE on the urbanization in inland cities are significantly weaker than in coastal cities, indicating that capital and power have little impact on the urbanization in inland cities. The reasons are as follows: first, the strength of REI and PCFE in the less developed inland areas are generally not high, and both play a limited role in promoting urbanization. Second, the degree of marketization and the level of urban public services in the inland cities are both low. Therefore, it is reasonable to speculate that other factors have important influences 
on urbanization in Central and Western China, and these factors have not been quantified by the model. Relatively, the impact of URIR on urbanization in inland cities is greater than in coastal cities, which indicates that class has a greater impact on the urbanization in inland cities. Besides, this implies that urbanization helps to break the urban-rural dual structure.

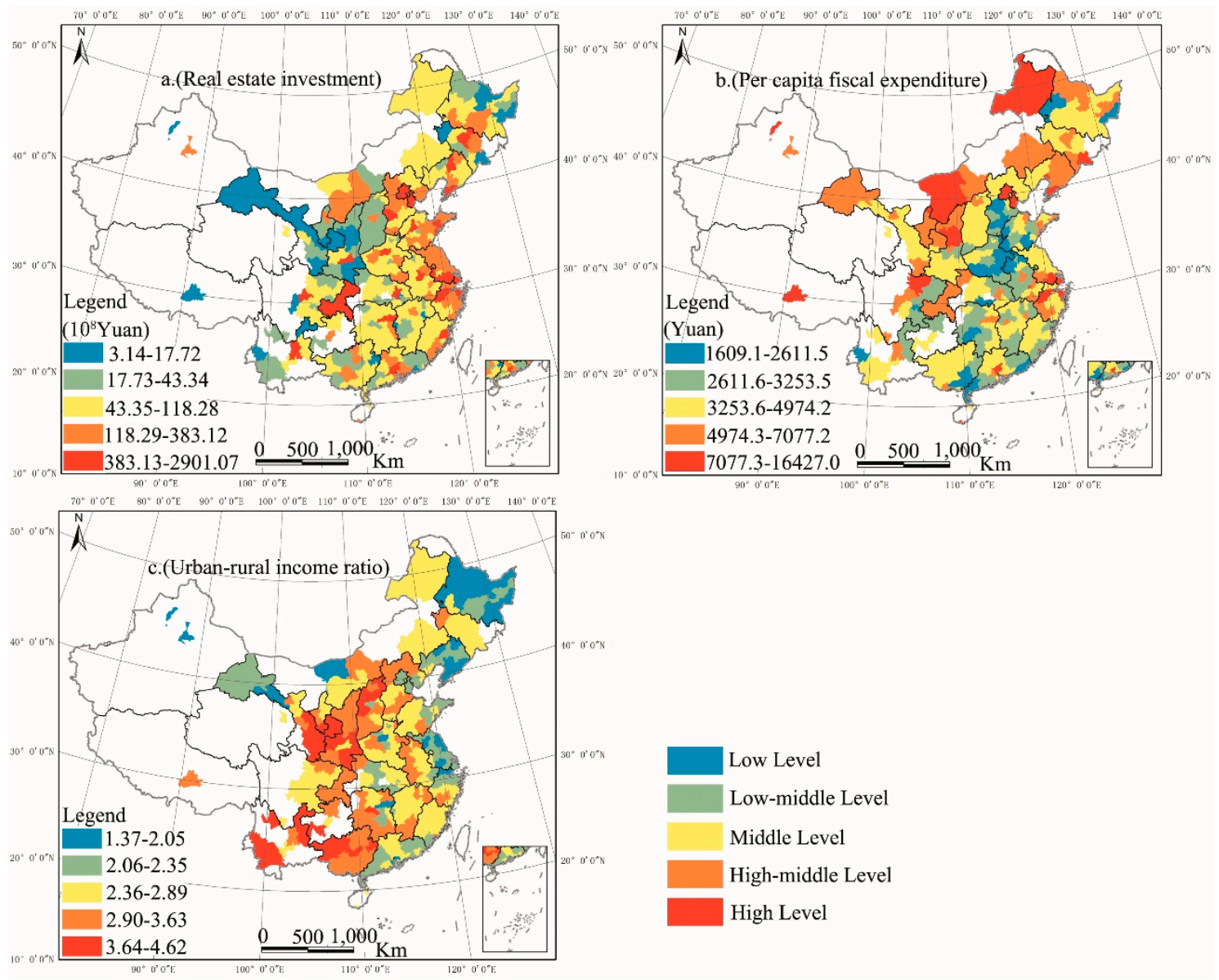

Figure 4. The spatial distribution of the influencing factors of urbanization in China.

Table 3. Detection results of potential determinants of urbanization in China.

\begin{tabular}{cccc}
\hline & REI & PCFE & URIR \\
\hline All prefecture-level cities & 0.3199 & 0.3305 & 0.2678 \\
Coastal prefecture-level cities & 0.4048 & 0.4611 & 0.1959 \\
Inland prefecture-level cities & 0.2420 & 0.2603 & 0.2443 \\
\hline
\end{tabular}

\section{Discussion}

Along with increased globalization and the deepening marketization of China's economy, China has experienced unprecedented rapid urbanization. China's urbanization not only determines China's future, but also determines the process of urbanization around the world. Compared with other countries, China differs, to a certain extent, in the factors influencing urbanization due to its unique urbanization model; rather, a unique political-economic dynamic is at play. Under the current political and economic structure and social production mode in China, there are significant differences in the impacts of capital, power, and class on the spatial production of urbanization. Capital and power interact and reshape urbanization pattern in China. China's urbanization is a hybrid process, in which capital and power conspire to produce an unprecedented phenomenon of rapid urbanization. However, this rapid urbanization is by no means without problems, and a series of phenomena underlying 
it deserve our attention, given the profound impact on cities and rural areas. In order to achieve rapid economic development, local governments often consider the accelerating of the process of urbanization as a breakthrough, regardless of local realities, blindly expanding the urban built-up area. There has been an unprecedented 'building cities' movement, such as the development zone fever in many places, the construction of new towns and new areas and the growing phenomenon of 'ghost cities' [10], leading to the loss of a large number of high-quality arable land and the risk associated with food security and safety. China is the most populous country in the world, and the per capita arable land area is far below the world average. China is facing a severe challenge in terms of scarcity of arable land, which is further aggravated by the accelerated urban expansion. Simultaneously, the rights and interests of farmers have also been limited and encroached upon, and this group is being artificially marginalized. Many young and middle-aged rural laborers are flowing into the cities, bringing sufficient labor force to the cities, but also causing a large amount of high-quality arable land to be abandoned. More importantly, the migrant population in cities, restricted by the household registration system, cannot enjoy many privileges like education, medical care, subsided housing, and pensions provided by the city government. They tend to live in urban villages with poor living conditions and are engaged in low-paying '3D' jobs (dirty, difficult, and dangerous).

The detailed empirical analysis in this paper can help Chinese urbanization strategy makers to pay attention to the regional differences in China's urbanization levels. As a socialist country, China's new-type urbanization space practice should balance the relationships between capital, power, and class. It is encouraging to see that Chinese leaders have recognized the serious problems arising from past urbanization models. In March 2014, the Central Committee of the Communist Party of China and the State Council jointly issued the "National New-type urbanization Plan (2014-2020)", the most salient aspect of which was the transition from land-centered urbanization to people-oriented urbanization [10]. Premier Li Keqiang is also concerned about urbanization in the central and western regions. At the end of November 2014, when he attended a science exhibition on human settlement at the National Museum, he proposed that the central and western regions need to be urbanized like the eastern regions, so that people in the central and western regions can benefit from modernization.

Chinese cities have undergone dramatic spatial transformations since the late 1970s. Compared with the structural changes experienced by the former Soviet Union and Eastern and Central European countries that broke away from socialism, China's urban development trajectory is quite different. The former adopted a shock therapy to rapidly transition from a socialist society to a capitalist society, whereas China's socio-economic transformation is known for its gradualist and experimental programs [29]. Therefore, the uniqueness of China's urban transformation means that neither theories of recentralization (authoritarian practices) nor decentralization (neoliberal) can fully explain the mechanisms of recent urban transformation in China. Theories, such as 'neoliberalism', 'growth coalition', or 'urban entrepreneurialism', that successfully interpret the spatial production of Western cities, but these theories can only be partially applied to Chinese cities [47]. Conversely, the spatial production of Chinese cities is driven by a hybrid economic and political force; it is simultaneously subject to the impacts both government and marketable interventions. It is argued that, as China continues to integrate into the global economy, the market plays an increasingly important role in shaping China's urbanization process, but China cannot ignore the role of the government in explaining the driving mechanisms of urbanization. As the Chinese economy is inherently political [29], a political economy perspective should be foregrounded to enrich our understanding of the complexity of China's urbanization process. As McGee [36] argued, Lefebvre's theory of spatial production provides the most effective approach for the study of China's urbanization process because a political economy perspective it adopts helps identify the main forces in the process of urbanization in transition economies. In this regard, we innovatively applied the theory of spatial production to the study of the driving forces of China's urbanization, fully considering the hybridity and uniqueness of urban spatial production in China, thus accounting for the shortcomings of the conventional 
Western-origin theories in explaining the spatial production of urbanization in China, which has important theoretical significance.

Although some studies have been reported on the driving forces of China's urbanization process from a traditional perspective, few studies have focused on the influencing factors using spatial production theory, and no index system has been selected to evaluate the extent of production of space. Particularly pertinent to the present study, Ye et al. [40] found that the forces from capital and power greatly contribute to rapid urbanization and the high urbanization level in Jiangsu Province, China. However, the research by Ye et al. was limited to the quantitative measurement of the selected factors. Ye et al. only qualitatively described the impacts of selected factors on urbanization in Jiangsu Province, China. It is necessary to mention that these selected factors may not be statistically significant. From the perspective of methodology, we highlighted the application prospects of the combination of regression analysis and the geographical detector technique to study the influencing factors that lie behind China's rapid urbanization. Our empirical analysis was used to examine the factors that influence urbanization differentiation in prefecture-level cities in China, which will help Chinese policy makers to formulate more detailed and geographically specific urbanization development strategies.

Our study does have a few limitations. First, due to the influence of administrative division adjustment and data acquisition restrictions, we only selected 2010 as the research year, and did not compare and analyze the cross-sectional data of different years. The factors influencing urbanization are a dynamic process that changes with the increase in productivity. With the release of the seventh National Population Census in 2020, data will be available for comparison. Second, indicators that represent capital, power, and class still lack a widely accepted standard, and the differences in the selection of evaluation indicators may have had a certain impact on the results of the study. Except for the socio-economic factors involved in this paper, the process of urbanization is also affected by geographical and historical factors. The high level of urbanization in the three northeastern provinces (Heilongiiang, Jilin, and Liaoning), for example, may be explained by the historical fact that the industrial development in these provinces was relatively developed during the Japanese colonial period in the 1930s and was further promoted by the aid of the Soviet Union in the 1950s. The levels of urbanization in some poor provinces in Northwestern China (Xinjiang and Inner Mongolia) are also relatively high, which may reflect local geographical conditions of dry land and desert, and a high degree of population concentration may reduce the cost of living in water-scarce areas [30].

The impact of terrain on urbanization cannot be ignored. Previous studies have shown that the smaller the terrain relief, the higher the urbanization rate [21]. It can be clearly seen from the spatial differentiation pattern of China's urbanization that the urbanization level in plains areas is significantly higher than in mountainous areas. With the development of the social economy and the improvement in market-oriented degree, the influences of natural factors on regional urbanization process have weakened, while the impacts of socio-economic factors on the process of urbanization have increased, but the effects of natural factors on urbanization do exist. Because of the neglect of these factors, the analysis for the determinants of urbanization in this paper is not sufficiently comprehensive enough. Therefore, determining how to explore the factors affecting urbanization in a deeper and more comprehensive way is the focus of future research.

\section{Conclusions}

We analyzed the distribution of urbanization in prefecture-level cities in China, and examined the driving forces based on the developed conceptual framework. We found that the urbanization pattern in China has two characteristics: administrative hierarchy and spatial agglomeration. This means that power plays an important role in the differentiation pattern of urbanization in China. The administrative hierarchy of a city represents the power of local government in China; higher administrative ranks tend to correspond to stronger policy-making power. The impact of spatial agglomeration effect on the distribution of urbanization was also demonstrated, which can be seen as the result of market forces (agglomeration externalities or overflow effect). In short, the distribution 
of urbanization in China is influenced by both capital and power. This inference is consistent with the results of the regression model and the geographical detector technique. From the results it can be seen that all research units in the econometric models, capital, and power play a positive role in the distribution of urbanization and have a greater impact on this distribution pattern, which again indicates that capital and power work in conjunction to produce the distribution of urbanization in China. The impact of class on urbanization is larger in inland cities than in coastal cities, which means that the promotion of urbanization will help to break the urban-rural dual structure.

Although recentralization or decentralization can partly explain the spatial production of urbanization in China, the dynamic interactions between government and market are much more intricate in China than in other countries. China's urbanization process is constrained not only by market development, but also by the government's constant participation in various things. This is different from many developed countries. In developed countries, the market plays a decisive role in the urbanization process; in China, ignoring the power of the government to explain the urbanization process is by no means perfect. Although the market plays an important role in the urbanization process, the power of the government can be observed in all aspects. Therefore, when studying the driving mechanisms of urbanization in China, we must focus on the 'political' aspect. As the political-economic and historical contexts of China are so different from the Western experience. Therefore, the theories of urban behavior, economic development theory, and urban-rural difference theory formulated out of the study of urbanization in developed Western countries are insufficient to explain the spatial production of urbanization in China. We therefore think that, within a broader framework of political economy theory, theoretical approaches that emphasize the role of institutions in economic, social, and political change provide the most valuable theoretical insights. We found that Lefebvre's theory is most helpful in examining the determinants of urbanization. Our empirical results also show that capital and power do play an important role in the spatial production of urbanization in China, which is in perfect agreement with Lefebvre's theory of spatial production. From this point of view, it was important that we innovatively used spatial production theory to examine the determinants of urbanization in transitional economies, not only because it complements the inadequate explanation for urbanization process in transitional economies by Western urbanization theory, but also provides the most appropriate interpretation framework for the spatial production of urbanization in these countries. We found that the driving mechanisms of the urbanization in different countries are quite different. Therefore, we cannot explain the formation mechanisms behind the urbanization process in all countries with one or several theories, but each examination should be rooted in the specific reality of a given country and urbanization theories should be that are suitable for the national conditions.

Some policy implications are worth mentioning. First, China's policy makers should recognize the huge gap in regional urbanization levels, which is not conducive to the realization of China's new-type urbanization. Equitable policies should be implemented in inland areas to narrow the urbanization gap between the inland and coastal provinces. Second, the current cadre assessment system should be reformed. Under the current performance appraisal system, local officials often build spacious squares and large roads to attract the attention of higher-level government in order to achieve successful promotions. Local governments often collude with developers to produce new cities and new districts that can be seen everywhere in the country, many of which have become 'ghost cities' for a variety of reasons. Third, the urbanization in inland areas needs to be strongly and urgently promoted. This will not only enable people in the central and western regions to enjoy modernization, but also help to break the urban-rural dual structure.

Author Contributions: Z.Y. conceived and designed the paper framework; J.-G.L. analyzed the data; J.L. wrote the paper. All authors read and approved the final manuscript.

Funding: The current work is the Strategic Priority Research Program of Chinese Academy of Sciences, Pan-Third Pole Environment Study for a Green Silk Road (Pan-TPE) (no. XDA20040400).

Conflicts of Interest: The authors declare no conflict of interest. 


\section{References}

1. Chen, M.; Lu, D.; Zha, L. The comprehensive evaluation of China's urbanization and effects on resources and environment. J. Geogr. Sci. 2010, 20, 17-30. [CrossRef]

2. Cohen, B. Urbanization in developing countries: Current trends, future projections, and key challenges for sustainability. Technol. Soc. 2006, 28, 63-80. [CrossRef]

3. Chen, J. Rapid urbanization in China: A real challenge to soil protection and food security. Catena 2007, 69, 1-15. [CrossRef]

4. Bloom, D.E.; Canning, D.; Fink, G. Urbanization and the Wealth of Nations. Science 2008, 319. [CrossRef] [PubMed]

5. Chen, M.; Liu, W.; Tao, X. Evolution and assessment on China's urbanization 1960-2010: Under-urbanization or over-urbanization? Habitat Int. 2013, 38, 25-33. [CrossRef]

6. Yang, X.J. China's Rapid Urbanization. Science 2013, 342. [CrossRef] [PubMed]

7. Bai, X.; Shi, P.; Liu, Y. Realizing China's urban dream. Nature 2014, 509. [CrossRef]

8. Cao, S.; Lv, Y.; Zheng, H.; Wang, X. Challenges facing China's unbalanced urbanization strategy. Land Use Policy 2014, 39, 412-415. [CrossRef]

9. Deng, X.; Bai, X. Sustainable Urbanization in Western China. Environment 2014, 56, 12-24. [CrossRef]

10. Chen, M.; Liu, W.; Lu, D. Challenges and the way forward in China's new-type urbanization. Land Use Policy 2015, 55, 334-339. [CrossRef]

11. UNPD (United Nations Population Division). World Urbanization Prospects: The 2018 Revision; United Nations: New York, NY, USA, 2018.

12. Chen, M.; Zhang, H.; Liu, W.; Zhang, W. The global pattern of urbanization and economic growth: Evidence from the last three decades. PLoS ONE 2014, 9, e103799. [CrossRef] [PubMed]

13. Seto, K.C.; Sánchez-Rodríguez, R.; Fragkias, M. The New Geography of Contemporary Urbanization and the Environment. Annu. Rev. Environ. Resour. 2010, 35, 167-194. [CrossRef]

14. Chang, G.H.; Brada, J.C. The paradox of China's growing under-urbanization. Econ. Syst. 2006, 30, $24-40$. [CrossRef]

15. Zhang, K.H.; Song, S. Rural-urban migration and urbanization in China: Evidence from time-series and cross-section analyses. China Econ. Rev. 2003, 14, 386-400. [CrossRef]

16. Zhao, S.X.B.; Chan, R.C.K.; Sit, K.T.O. Globalization and the dominance of large cities in contemporary China. Cities 2003, 20, 265-278. [CrossRef]

17. Güneralp, B.; Seto, K.C. Environmental impacts of urban growth from an integrated dynamic perspective: A case study of Shenzhen, South China. Glob. Environ. Chang. Hum. 2008, 18, 720-735. [CrossRef]

18. Chen, M.; Huang, Y.; Tang, Z.; Lu, D.; Liu, H.; Ma, L. The provincial pattern of the relationship between urbanization and economic development in China. J. Geogr. Sci. 2014, 24, 33-45. [CrossRef]

19. He, C.; Chen, T.; Mao, X.; Zhou, Y. Economic transition, urbanization and population redistribution in China. Habitat Int. 2016, 51, 39-47. [CrossRef]

20. Zhu, J. Transition of villages during urbanization as collective communities: A case study of Kunshan, China. Cities 2018, 72, 320-328. [CrossRef]

21. Wang, J.; Li, Y. Spatial pattern and influencing factors of urbanization development in China at county level: A quantitative analysis based on 2000 and 2010 census data. Acta Geogr. Sin. 2016, 71, 621-636. (In Chinese) [CrossRef]

22. Guan, X.; Wei, H.; Lu, S.; Deng, Y. Patterns and driving mechanism of spatialagglomeration during the urbanization process in China. Geogr. Res. 2016, 35, 227-241. (In Chinese) [CrossRef]

23. Shen, J.; Lin, L. State-sponsored and spontaneous urbanization in Fujian province of China, 1982-2010. Cities 2017, 60, 420-427. [CrossRef]

24. Shen, J.; Wong, K.-Y.; Feng, Z. State-sponsored and spontaneous urbanization in the Pearl River Delta of South China, 1980-1998. Urban Geogr. 2002, 23, 674-694. [CrossRef]

25. Shen, J. Understanding dual-track urbanisation in post-reform China: Conceptual framework and empirical analysis. Popul. Space Place 2006, 12, 497-516. [CrossRef]

26. Shen, J.; Feng, Z.; Wong, K.-Y. Dual-track urbanization in a transitional economy: The case of Pearl River Delta in South China. Habitat Int. 2006, 30, 690-705. [CrossRef] 
27. Sit, V.F.S.; Yang, C. Foreign-investment-induced Exo-urbanisation in the Pearl River Delta, China. Urban Stud. 1997, 34, 647-677. [CrossRef]

28. Feng, Y.; Kugler, J.; Zak, P.J. Population Growth, Urbanisation and the Role ofm Government in China: A political economic model of demographic change. Urban Stud. 2002, 39, 2329-2343. [CrossRef]

29. Ma, L.J.C. Urban transformation in China, 1949-2000: A review and research agenda. Environ. Plan. A 2002, 34, 1545-1569. [CrossRef]

30. Zhang, K.H. What explains China's rising urbanisation in the reform era? Urban Stud. 2002, 39, $2301-2315$. [CrossRef]

31. Zhou, Y.; Ma, L.J.C. China's urbanization levels: Reconstructing a baseline from the fifth population census. China Q. 2003, 176-196. [CrossRef]

32. Zhang, L. Conceptualizing China's urbanization under reforms. Habitat Int. 2008, 32, 452-470. [CrossRef]

33. Heikkila, E.J. Three questions regarding urbanization in China. J. Plan. Educ. Res. 2007, 27, 65-81. [CrossRef]

34. Young, D.; Deng, H. Urbanisation, agriculture and industrialisation in China, 1952-1991. Urban Stud. 1998, 35, 1439-1455. [CrossRef]

35. Liu, T.; Qi, Y.; Cao, G.; Liu, H. Spatial patterns, driving forces, and urbanization effects of China's internal migration: County-level analysis based on the 2000 and 2010 censuses. J. Geogr. Sci. 2015, 25, 236-256. [CrossRef]

36. McGee, T.G. Interrogating the production of urban space in China and Vietnam under market socialism. Asia Pac. Viewp. 2009, 50, 228-246. [CrossRef]

37. Lefebvre, H. The Production of Space; Blackwell Press: Oxford, UK, 1991; pp. 33-39.

38. Zhuang, L.; Ye, C. Disorder or reorder? The spatial production of State-Level New Areas in China. Sustainability 2018, 10, 3628. [CrossRef]

39. Ye, C.; Chen, M.; Chen, R.; Guo, Z. Multi-scalar separations: Land use and production of space in Xianlin, a university town in Nanjing, China. Habitat Int. 2014, 42, 264-272. [CrossRef]

40. Ye, C.; Chen, M.; Duan, J.; Yang, D. Uneven development, urbanization and production of space in the middle-scale region based on the case of Jiangsu province, China. Habitat Int. 2017, 66, 106-116. [CrossRef]

41. Brenner, N. The urban question: Reflections on Henri Lefebvre, urban theory and the politics of scale. Int. J. Urban Reg. Res. 2000, 24, 361-378. [CrossRef]

42. Brenner, N. State territorial restructuring and theproduction of spatial scale:Urban and regional planning in the Federal Republic of Germany, 1960-1990. Polit Geogr. 1997, 16, 273-306. [CrossRef]

43. Buser, M. The production of space in metropolitan regions: A Lefebvrian analysis of governance and spatial change. Plan. Theory 2012, 11, 279-298. [CrossRef]

44. Klink, J. Development regimes, scales and state spatial restructuring: Change and continuity in the production of urban space in metropolitan Rio de Janeiro, Brazil. Int. J. Urban Reg. Res. 2013, 37, 1168-1187. [CrossRef]

45. Leary, M.E. A Lefebvrian analysis of the production of glorious, gruesome public space in Manchester. Prog. Plan. 2013, 85, 1-52. [CrossRef]

46. Nasongkhla, S.; Sintusingha, S. Social Production of Space in Johor Bahru. Urban Stud. 2013, 50, $1836-1853$. [CrossRef]

47. Li, Z.; Li, X.; Wang, L. Speculative urbanism and the making of university towns in China: A case of Guangzhou University Town. Habitat Int. 2014, 44, 422-431. [CrossRef]

48. NBSC (National Bureau of Statistics of China). China City Statistical Yearbook 2011; China Statistical Press: Beijing, China, 2011.

49. NBSC (National Bureau of Statistics of China). China Statistical Yearbook for Regional Economy 2011; China Statistical Press: Beijing, China, 2011.

50. Wang, F.; Zhou, Y. Modelling urban population densities in Beijing 1982-1990: Suburbanisation and its causes. Urban Stud. 1999, 36, 271-287. [CrossRef]

51. Feng, J.; Zhou, Y.; Wu, F. New trends of suburbanization in Beijing since 1990: From government-led to market-oriented. Reg. Stud. 2008, 42, 83-99. [CrossRef]

52. Friedmann, J. Four theses in the study of China's urbanization. Int. J. Urban Reg. Res. 2006, 30, 440-451. [CrossRef]

53. Chen, M.; Lu, D.; Zhang, H. Comprehensive evaluation and the driving factors of China's urbanization. Acta Geogr. Sin. 2009, 64, 387-398. (In Chinese) 
54. Sun, Y. The relationship between urbanization and real estate empirical research based on the data of Shandong Province. Int. J. Manag. Stud. Res. 2014, 2, 36-40.

55. O'Sullivan, A. Urban Economics, 8th ed.; Douglas Reiner: New York, NY, USA, 2012.

56. Lampard, E.E. The history of cities in the economically advanced areas. Econ. Dev. Cult. Chang. 1955, 3, 81-136. [CrossRef]

57. Liu, T.-Y.; Su, C.-W.; Chang, H.-L.; Chu, C.-C. Is urbanization improving real estate investment? A cross-regional study of China. Rev. Dev. Econ. 2018, 22, 862-878. [CrossRef]

58. Linn, J.F. The costs of urbanization in developing countries. Econ. Dev. Cult. Chang. 1982, 30, $625-648$. [CrossRef]

59. Davis, J.C.; Henderson, J.V. Evidence on the political economy of the urbanization process. J. Urban Econ. 2003, 53, 98-125. [CrossRef]

60. Yu, H. Empirical analysis to urbanization and financial policy in China. Stat. Thinktank 2008, 60-64. (In Chinese)

61. Liu, H. An empirical analysis of the relevance between urbanization development and fiscal policy. Sub Natl. Fiscal Res. 2013, 52-55. (In Chinese)

62. Todaro, M.P. A model of labor migration and urban unemployment in less developed countries. Am. Econ. Rev. 1969, 59, 138-148. [CrossRef]

63. Lewis, W.A. Economic development with unlimited supplies of labour. Manch. Sch. 1954, 139-181. [CrossRef]

64. Cai, L.; Yao, W. The influence to the new urbanization by the change of incom gap between urban and rural areas: Based on provincial panel data. J. Lingnan Normal Univ. 2017, 38, 78-86. (In Chinese)

65. Li, J. An empirical study on the relationship between urbanization and urban-rural income gap in Inner Mongolia. Money China 2018, 1-12. (In Chinese)

66. Wang, Y.; Wang, S.; Li, G.; Zhang, H.; Jin, L.; Su, Y.; Wu, K. Identifying the determinants of housing prices in China using spatial regression and the geographical detector technique. Appl. Geogr. 2017, 79, $26-36$. [CrossRef]

67. Wang, S.; Wang, J.; Wang, Y. Effect of land prices on the spatial differentiation of housing prices: Evidence from cross-county analyses in China. J. Geogr. Sci. 2018, 28, 725-740. [CrossRef]

68. Cheng, T.; Selden, M. The origins and social consequences of China's hukou system. China Q. 1994, 139, 644-668. [CrossRef]

69. Chen, J.; Guo, F.; Wu, Y. One decade of urban housing reform in China: Urban housing price dynamics and the role of migration and urbanization, 1995-2005. Habitat Int. 2011, 35, 1-8. [CrossRef] 